\title{
Angelina Jolie's faulty gene: newspaper coverage of a celebrity's preventive bilateral mastectomy in Canada, the United States, and the United Kingdom
}

\author{
Kalina Kamenova, PhD ${ }^{1}$, Amir Reshef, MBA ${ }^{1}$ and Timothy Caulfield, LLM, FRSC ${ }^{1,2}$
}

\begin{abstract}
Purpose: This study investigates the portrayal of Angelina Jolie's preventive bilateral mastectomy in the news media. Content analysis of print news was conducted to identify major frames used in press coverage, the overall tone of discussions, how journalists report broader questions about BRCA1/2 testing and hereditary breast/ovarian cancer, and whether they raise concerns about the impact of celebrities on patients' choices and public opinion.
\end{abstract}

Methods: The Factiva database was used to collect publications on Jolie's preventive mastectomy in elite newspapers in Canada, the United States, and the United Kingdom. The data set consisted of 103 newspaper articles published in the first month of media coverage.

Results: The results show that although the press discussed key issues surrounding predictive genetic testing and preventive options for

\section{INTRODUCTION}

On 14 May 2013, Angelina Jolie made headlines throughout the world with the announcement that she was a carrier of a $B R C A 1$ genetic mutation that significantly increases the risk for breast and ovarian cancer and that she had hence chosen to undergo preventive bilateral mastectomy with reconstructive surgery. In an op-ed piece in The New York Times, the actress indicated that the inherited genetic mutation increased her risk for breast cancer to $87 \%$ and for ovarian cancer to $50 \%$, and she discussed the medical procedures involved in mastectomies. ${ }^{1}$ She also expressed concern that the high cost of BRCA1/2 testing (suggesting it is "at more than $\$ 3,000$ in the United States") could limit cancer prevention options for many women. ${ }^{1}$ The US National Cancer Institute estimates that women who have inherited a deleterious mutation in the BRCA1 or BRCA2 gene are at significantly greater risk for developing breast and/or ovarian cancer than women who do not have such mutations. ${ }^{2}$ Data indicate that $55-65 \%$ of women with harmful BRCA1 mutations and $45 \%$ of women with harmful BRCA2 mutations will develop breast cancer during their lives, as compared with only $12 \%$ of women in the general population who will develop the disease. ${ }^{2}$

Due to her iconic celebrity status, Jolie's disclosure of her predisposition to hereditary breast/ovarian cancer quickly brought the issues of genetic testing and preventive mastectomy into women at high risk of hereditary breast/ovarian cancer, important medical information about the rarity of Jolie's condition was not communicated to the public.

Conclusion: The results highlight the media's overwhelmingly positive slant toward Jolie's mastectomy, while overlooking the relative rarity of her situation, the challenges of "celebrity medicine," and how celebrities influence people's medical decisions. Future research is required to investigate whether the media hype has influenced demand and use of BRCA1/2 testing and preventive mastectomies.

Genet Med advance online publication 19 December 2013

Key Words: BRCA genetic testing; content analysis; hereditary breast and ovarian cancer; newspapers; preventive mastectomy

the limelight. Yet BRCA1/2 testing has been the subject of continuous policy debate in relation to its cost, access, and clinical benefits. ${ }^{3}$ In Canada, concerns in the past have revolved around the inability of the public health-care system to provide comprehensive and timely access to genetic tests and counseling. ${ }^{4}$ This was exemplified by the case of Fiona Webster, an Ontario woman who was at risk of hereditary breast cancer but was denied testing. In 1999 she successfully challenged the Ontario Health Insurance Plan to cover BRCA screening as an essential medical service. ${ }^{5}$ In the United States, the recent Myriad patent controversy has brought the issue of $B R C A 1 / 2$ testing to the public's attention, and this type of genetic testing has thereby received significant media coverage.

Physicians and scientists have often been wary of the ways in which the media portray important health issues, particularly the tendency of sensationalism in medical reporting and miscommunication of scientific data, which may diminish the ability of the public to participate as knowledgeable participants in policy debates. ${ }^{6,7}$ In the context of genetic research, the term "genohype" has been offered to describe inaccurate portrayals and exaggerated claims about DNA and genetics in the popular media. ${ }^{8}$ Although genetic research has been accurately reported in the English-speaking media, news articles have tended to overemphasize benefits and underplay risks of new discoveries. ${ }^{9}$ The policy implications of such media representations are

${ }^{1}$ Health Law Institute, Faculty of Law, University of Alberta, Edmonton, Alberta, Canada;. ${ }^{2}$ Faculty of Law and School of Public Health, University of Alberta, Edmonton, Alberta,

Canada. Correspondence: Timothy Caulfield (caulfield@ualberta.ca) 
significant because overly optimistic assessments of new technologies can create unrealistic expectations in patients and influence how these technologies are used in clinical practice. ${ }^{10}$

In this article, we examine how Jolie's decision to undergo preventive mastectomy has been portrayed in major newspapers in three countries-Canada, the United States, and the United Kingdom. The timing of the story coincided with the US Supreme Court deliberations in the case of Association for Molecular Pathology v. Myriad Genetics, ${ }^{11}$ and its relevance to the case may have contributed to the significant media attention it received. We conducted content analysis of print news to identify major frames in press coverage and to illustrate, in the context of Jolie's story, how the media reports broader issues concerning BRCA1/2 testing and preventive medicine. Furthermore, we looked into whether journalists raised concerns about the role of celebrities in influencing patients' medical decisions and public opinion in general.

Given the impact that media can have on public opinion, policy development, and demand for health services, the broader implications of the Jolie phenomenon are worth considering. Health-care providers often view media representations as a significant driver of patient interest in genetic testing. ${ }^{4}$ We have seen that on issues such as cosmetic surgery ${ }^{12}$ and cancer screening, ${ }^{13}$ celebrities have had a significant impact on individual health-related decisions. A study about cancer reporting in Australian TV news has found that celebrities appear central to news coverage of specific cancers, especially breast cancer, which is the most reported cancer on television. ${ }^{14}$ The media coverage of Kylie Minogue's breast cancer diagnosis in 2005 led to an unprecedented increase in screening by mammography in Australia. ${ }^{15}$ In addition, decisions by prominent public figures to select specific cancer treatments have often influenced medical choices made by the general population. Nancy Reagan's decision to pursue mastectomy versus breast-conserving surgery after her breast cancer diagnosis in late 1987 led to a decrease in breast-conserving surgery, particularly in her demographic group of women aged 50-79 years and among women with lower income and educational status. ${ }^{16}$ Mass media coverage of public figures' experiences with cancer can also increase cancer awareness and the use of early detection tests as indicated by the impact of President Reagan's colon cancer case in $1985 .^{17}$

\section{News media portrayals of biomedical science}

Mass media, together with the general education system, constitute the primary source of health information for the public. ${ }^{18}$ Lay people rely heavily on media sources and media professionals for information and interpretation on critical scientific debates, especially when they attempt to understand science in ways that relate to their own lives. ${ }^{19}$ The news media can significantly influence the public communication of controversial science through their ability to provide legitimacy to expert knowledge and filter information they convey to audiences. The media also traditionally provide a forum for policy debates on controversial health issues. ${ }^{20}$
The media can influence their audience through two related processes: framing and agenda setting. The concept of "framing" emphasizes the selective presentation of specific topics, facts, controversies, actors, and assertions in news stories. ${ }^{21,22}$ Frames are routinely used in news reporting to call attention to some aspects of reality while obscuring other elements. These interpretive story lines provide a context within which to understand the issues being presented and can significantly influence the audiences' perceptions by limiting the range of interpretations on complex topics. Previous research has shown that media have the ability to frame scientific controversies in ways that greatly influence societal perceptions and shape science policy debates. $^{23-25}$ Furthermore, McCombs and Shaw ${ }^{26}$ have established that the main effect of news media is agenda settingalthough media cannot tell people what to think, they can still influence what people think about by highlighting certain issues for public debate and excluding others from coverage. The media may also shape the ways in which individuals and communities participate in health-care decision making. ${ }^{27}$

\section{MATERIALS AND METHODS}

We used the Factiva Database to collect print news articles on Jolie's mastectomy from elite newspapers in three countriesCanada, the United States, and the United Kingdom. The following search terms were used: "Angelina Jolie" and "breast cancer" (or "ovarian cancer" or "gene"). Searches were limited to publications in the top five daily newspapers in a broadsheet format in each country, based on recent circulation data reports. ${ }^{28,29}$ Although tabloids sometimes have wider circulation than broadsheets (e.g., The Sun and Daily Mirror in the United Kingdom), the newspapers we selected are renowned for their high-quality reporting and authoritative comment on political and social issues. Certain criteria have been commonly used in the research literature to distinguish popular (tabloid) newspapers from elite (high-quality) press, particularly format, overall design, content, target audience, and journalistic ethics. ${ }^{30}$ We determined elite newspapers based on five distinctive features-large broadsheet format, tendency to include more text and longer articles, focus on "hard news" (i.e., national and international politics), intended for a more educated audience, and higher quality of journalism/high level of ethical practice. ${ }^{31}$ Extensive coverage of a story in such prestigious news sources can be an indication of the media salience of the issue.

The time period covered in the study includes 1 month of press coverage immediately following the breaking news of Jolie's prophylactic surgery, from 13 May to 12 June 2013. After excluding duplicates and irrelevant articles, the data set consisted of 103 newspaper articles (Table 1). Articles were considered irrelevant if the mention of "Angelina Jolie" was not linked to discussions of preventive mastectomy, breast cancer, ovarian cancer, BRCA1/2 testing, the Myriad controversy, cancer awareness and prevention, or women's health issues. Of the 103 included articles, 28 articles (27.2\%) were published in Canada, 41 (39.8\%) were published in the United States, and 34 (33\%) were published in the United Kingdom. 
Content analysis of relevant newspaper articles was conducted to examine how the media framed Jolie's preventive mastectomy. As an initial step, working frames were derived through an in-depth analysis of the articles. Frames were then defined in a codebook and coded in a qualitative content analysis. This inductive approach, albeit more subjective than structured methodologies, allows the identification of newly emerging media frames that remain obscured or overlooked in deductive studies that are traditionally limited to predefined frames. ${ }^{32}$ The coding frame included the following: (i) information about publication date, word count, article type, author or article source, newspaper section, and who was quoted or attributed with providing information or evidence; (ii) identification of the primary framing of Jolie's medical choice; (iii) mentions of the rarity of her condition; (iv) identification of the primary issue concerning the BRCA1/2 gene mutations; (v) discussions of surgical and alternative methods for breast cancer prevention, the cost and drawbacks of preventive mastectomies, the Myriad patent controversy, and cost associated with BRCA testing; (vi) how journalists interpreted the impact of the Jolie story, celebrity medicine, and benefits of evidence-based decision making; and (vii) the overall tone of the article. The tone of the article was assessed by looking at whether journalists presented Jolie's announcement of her prophylactic mastectomy in a positive, neutral, or negative light. Because this type of assessment involves subjective impression, coders were instructed to evaluate both the author's attitude toward the issue and the sides presented in the article. For example, an author may be writing in a neutral or descriptive tone but only opposing opinions are presented; subsequently, the tone of the article would be assessed as negative.

Table 1 Newspapers in data set

\begin{tabular}{llcc} 
Newspaper & Country & $\begin{array}{c}\text { No. of } \\
\text { articles }\end{array}$ & $\begin{array}{c}\text { Articles in } \\
\text { data set (\%) }\end{array}$ \\
\hline The Globe and Mail & Canada & 9 & 8.7 \\
\hline The Montreal Gazette & Canada & 3 & 2.9 \\
\hline National Post & Canada & 5 & 4.9 \\
\hline Toronto Star & Canada & 9 & 8.7 \\
\hline Vancouver Sun & Canada & 2 & 1.9 \\
\hline The Los Angeles Times & United States & 4 & 3.9 \\
\hline The New York Times & United States & 18 & 17.5 \\
\hline USA Today & United States & 10 & 9.7 \\
\hline The Wall Street Journal & United States & 4 & 3.9 \\
\hline The Washington Post & United States & 5 & 4.9 \\
\hline The Daily Telegraph & United Kingdom & 10 & 9.7 \\
\hline Financial Times & United Kingdom & 3 & 2.9 \\
\hline The Guardian & United Kingdom & 5 & 4.9 \\
\hline The Independent & United Kingdom & 3 & 2.9 \\
\hline The Times (London) & United Kingdom & 13 & 12.6 \\
\hline Total & & 103 & 100 \\
\hline
\end{tabular}

Because news content analysis is generally considered to be subjective, we tested $10 \%$ of the articles for intercoder reliability using Cohen's $\kappa$, particularly for variables that yield interpretive differences among independent coders. As shown in Supplementary Table S1 online, the intercoder reliability assessment produced a mean score of $k=0.724$, indicating substantial interrater agreement according to the criteria of Landis and Koch for interpreting $\kappa .{ }^{33} \kappa$ Scores on the coding frame categories ranged between 0.615 and 1.000 , showing substantial or almost perfect agreement, and only one category produced $k=0.583$, denoting moderate interrater agreement. The coders resolved disagreements on this category by consensus, and the coding results were adjusted accordingly.

\section{RESULTS}

We found that Jolie's preventive mastectomy attracted significant attention from the news media in each country. Most coverage occurred within the first 3 days after the breaking news of Jolie's surgery on 13 May 2013-44 articles (42.5\%) were published between 14 May and 16 May: 8 (7.8\%) on 14 May; $32(31.1 \%)$ on 15 May; and $14(13.6 \%)$ on 17 May. Subsequent coverage was less frequent, but media attention to the story remained steady in all three countries, as shown in Figure 1.

Common framing mechanisms of print media include placement of news stories within the media text, the use of visuals such as pictures and pull quotes, and other aesthetic devices to highlight a key topic and attract the reader's attention. Articles were coded to determine their type, source, and positioning as an indicator of prominence and salience. Results show that the story was prominently featured in the news section of elite newspapers, unlike the more traditional placement of celebrity news in the entertainment or lifestyle sections. Forty articles (38.8\%) were published in the news section, and 5 articles (4.9\%) were placed on the front page of newspapers. Furthermore, 32 articles $(31.1 \%)$ were news stories, $24(23.3 \%)$ were editorial or opinion pieces, $8(7.8 \%)$ were investigative reports, $9(8.7 \%)$

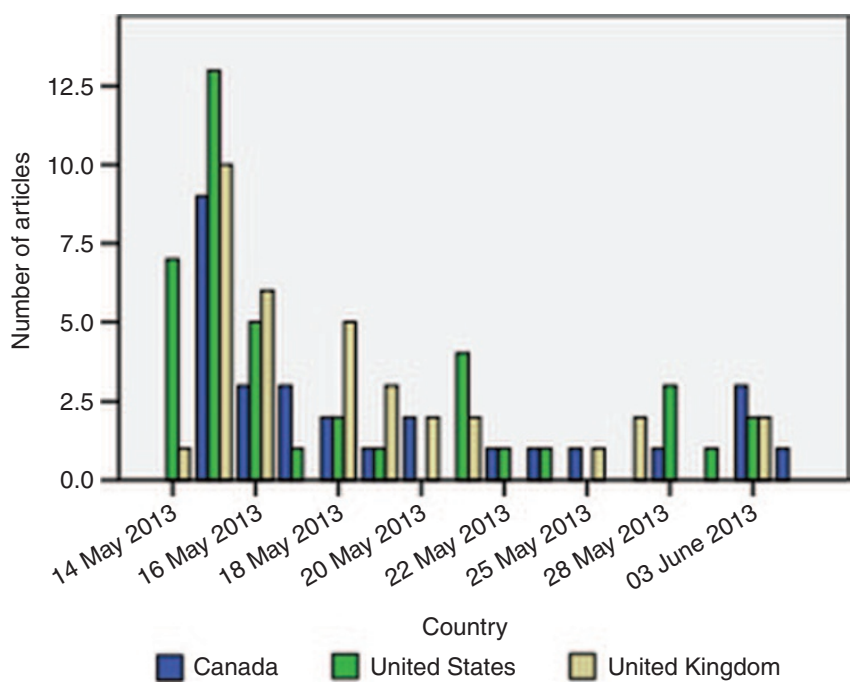

Figure 1 Press coverage of Angelina Jolie's preventive mastectomy. 
were columns, $8(7.8 \%)$ were health or lifestyle articles, and 22 (21.4\%) were categorized as "other" (e.g., interviews and letters to editor). More than half of the articles were written by journalists -43 articles $(41.7 \%)$ by staff writers, $10(9.7 \%)$ by regular columnists, and 5 ( $4.9 \%)$ by science/health writers, with only 3 (2.9\%) being wire service news.

We identified major frames in the media portrayal of Jolie's preventive bilateral mastectomy. The primary framing of Jolie's decision in 40 articles (38.8\%) was as "brave and courageous," in 23 articles (22.3\%) as "rational, well-informed, and evidence based," in 13 (12.6\%) as "empowering, inspiring, and a role model for other women," and in 4 (3.9\%) as "fearful and made under duress"; only one article framed it as "an act of narcissistic and attention-seeking celebrity" (Figure 2). There were no significant differences between countries, with the following distribution of articles with primary framing of Jolie's choice as "brave and courageous": 9 in Canada, 16 in the United States, and 15 in the United Kingdom. Primary framing of her decision as "rational, inspiring, or role model for women" was observed in 6 articles in Canada, 12 in the United States, and 5 in the United Kingdom.

Given that harmful $B R C A 1 / 2$ mutations are relatively rare in the general population and account for only $5-10 \%$ of all breast cancers, we searched for mentions of the rarity of Jolie's condition. Examples of such "rarity" discussions included the following: (i) information that BRCA1/2 mutations are rare and account for a small percentage of all breast cancers; (ii) mentions that Jolie's risk of developing breast and/or ovarian cancer was unusually high compared with that of most women; (iii) other mentions along these lines (e.g., that Jolie's situation is an exception, that it does not apply to everyone, and that most women who get breast cancer are not carriers of BRCA1/2



Figure 2 Media framing of Angelina Jolie's preventive mastectomy. mutations). Results show that such important medical information was communicated in only 33 articles $(32 \%$ of the data set) and that 70 news stories ( $68 \%$ of the data set) did not include discussions of the rarity of Jolie's condition. The following distribution of mentions of rarity was observed by country: 11 articles (10.7\%) in Canada, $14(13.6 \%)$ in the United States, and $8(7.8 \%)$ in the United Kingdom.

We coded the articles to determine how the media depict issues surrounding genetic testing for hereditary breast/ovarian cancer. The primary issue concerning $B R C A 1 / 2$ gene mutations highlighted in 72 articles (69.9\%) was the increased risk of hereditary breast/ovarian cancer. Other concerns were the primary focus of 23 articles (22.3\%), particularly the low percentage of women who carry BRCA1/2 mutations, the cost of genetic testing, the impact of predictive genetic testing on patients' mental health, or general discussions about preventive medicine. As shown in Figure 3, the increased risk of hereditary breast/ovarian cancer was the primary focus of discussion in all three countries, with 23 articles published in Canada, 27 in the United States, and 22 in the United Kingdom. Overall, 28 (27.2\%) of the articles included relatively extensive discussions of the high cost of BRCA1/2 testing. Of the 28 articles that tackled this issue, 17 were published in the United States, 7 in Canada, and only 4 in the United Kingdom.

The gene patenting controversy was discussed in 11 (10.7\%) of the news stories, 7 of which were published in the United States, 1 in Canada, and 3 in the United Kingdom. Nine articles suggested that striking down the Myriad patents on BRCA1/2 tests would lower the cost of genetic testing-one in Canada,

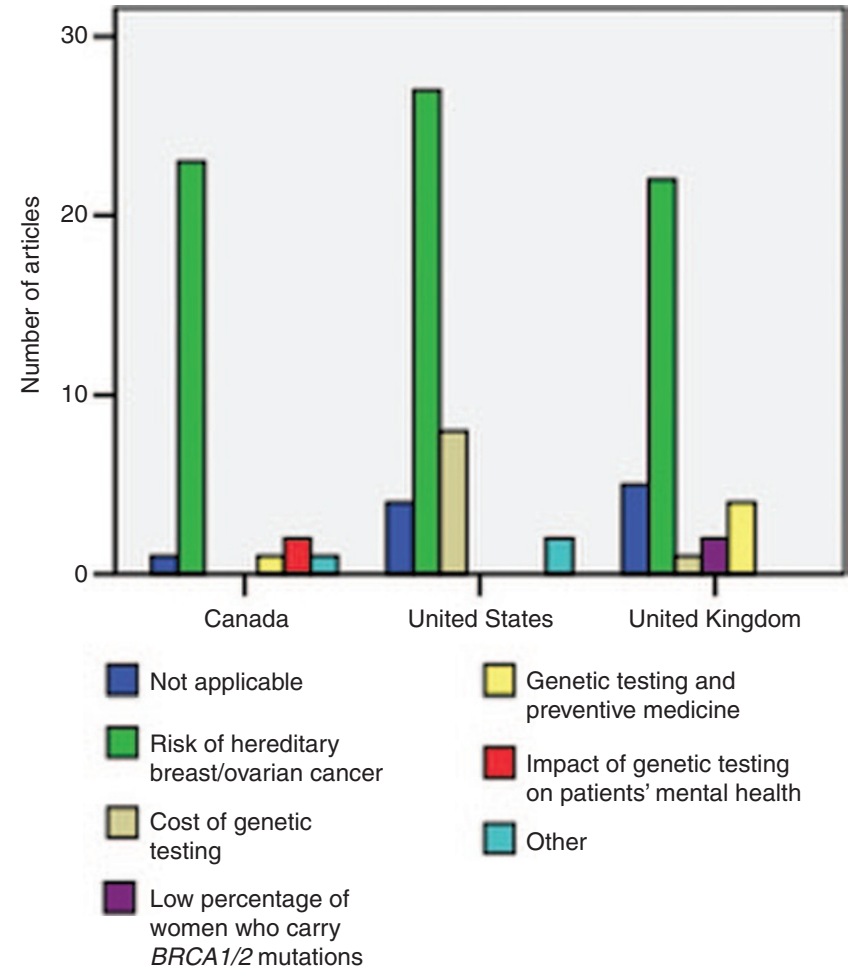

Figure 3 Primary issue concerning BRCA1/2 gene mutations. 
five in the United States, and three in the United Kingdom. Five articles expressed concerns that a decision by the Supreme Court to invalidate Myriad's gene patents would stifle innovation in biotechnology-one in Canada, three in the United States, and one in the United Kingdom. Only two articles suggested that invalidating patents of human genes would spur innovation in the biotechnology industry-one in Canada and one in the United States.

In the context of Jolie's preventive mastectomy, 28 articles (27.2\%) addressed the question of how effective surgical methods of breast cancer prevention were in comparison with alternatives such as clinical breast examination, mammography, thermography, breast biopsies, tamoxifen or raloxifene treatments, and lifestyle changes. Surgical methods for early prevention were described as being more effective in only eight articles (7.8\%), and there were even fewer claims that preventive mastectomy eliminates all risk of developing breast cancer-only three articles (2.9\%). Health professionals and scientific experts were cited or referenced as experts in 16 of the 28 articles that discussed the efficacy of surgical methods in comparison with that of other prophylactic methods.

Concerns that the hype around Jolie's mastectomy can influence women to opt for surgery without having a previous evidence-based assessment of their genetic risks were expressed in only 11 articles (10.7\%). Only 19 articles (18.4\%) mentioned the possible drawbacks of preventive mastectomy, e.g., the incidence of breast reconstruction prosthesis infection ${ }^{34}$ or the emotional or psychological consequences that mastectomies have on women, even in cases when the operation is immediately followed by breast reconstruction. ${ }^{35,36}$ When crosstabulated by country, the results showed discussions of these topics in six articles published in Canada, six articles in the United States, and seven in the United Kingdom. Nonetheless, 33 articles (32\%) did mention the benefits of evidence-based decisions regarding BRCA1/2 testing and genetic risk assessment. This concern was slightly more prominent in the UK press, with 15 articles including such discussions, as compared with 12 in the United States and 6 in Canada.

Journalists positively interpreted Jolie's role in bringing the issues of hereditary breast cancer and preventive medicine to the public's attention. Almost half of the articles in the data set indicated that the public announcement of her preventive mastectomy would raise awareness of BRCA1/2 testing and cancer prevention. Forty-nine news stories (47.6\%) included such claims, with the following distribution by country: 19 in the United Kingdom, 18 in the United States, and 12 in Canada.

Finally, the overall tone of discussions in each article was assessed. News portrayals were mainly positive and framed Jolie's medical choice as brave, inspiring, and raising public awareness about preventive options for women at high risk for hereditary breast/ovarian cancer (Figure 4). Fifty-nine articles (57.3\%) were supportive of Jolie's announcement, whereas 33 (32\%) presented it in a rather descriptive manner, and 6 (5.6\%) included both positive and negative evaluations and/or multiple perspectives. Only five articles (4.9\%), all of which were

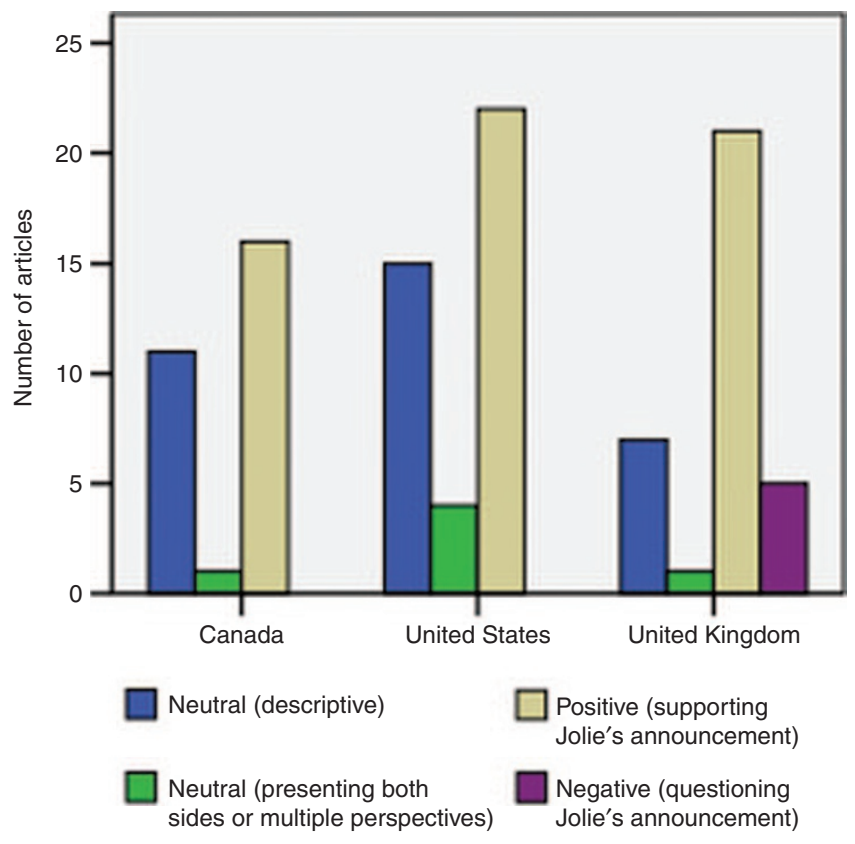

Figure 4 Overall tone of the articles.

published in UK newspapers, portrayed her decision in a negative light by questioning her motivation to make a public announcement. There was no significant variation in media representations among countries, with most articles either adopting a positive slant (16 in Canada, 22 in the United States, and 21 in the United Kingdom) or presenting the story in a descriptive manner (11 in Canada, 15 in the United States, and 7 in the United Kingdom).

\section{DISCUSSION}

Overall, there were similarities in newspaper portrayals of Jolie's mastectomy in the three countries. First, the story was prominently featured in the news sections of elite newspapers and received continuous coverage. Second, the media depicted Jolie's decision in a positive light, with most reports using emotive language in framing her medical choice. The major frame in media portrayal was that this was a brave and courageous decision. Third, newspaper articles often left out important medical information (e.g., $68 \%$ did not discuss the rarity of her condition). Fourth, the celebrity angle was dominant and the primary reason the story attracted so much attention. Although the press coverage included discussions of hereditary breast/ ovarian cancer, $B R C A$ testing, advances in genomics, and preventive medicine, this was primarily a news story about Jolie, thus highlighting the role of celebrities in public debates on these issues.

Although the results suggest that the tone of media coverage did not differ considerably among the three countries, discussions of the cost of predictive genetic testing occurred more frequently in the US media. Eight of the nine articles that framed the Jolie story primarily around the high-cost $B R C A 1 / 2$ testing and preventive mastectomies were published in US 
newspapers. Major concerns articulated by journalists included the high premiums charged by insurers, limited availability of plastic surgeons in some regions, and limited access to breast reconstruction surgery for Medicare recipients, given that few plastic surgeons accept this insurance.

Results indicate that newspapers were careful about how they were presenting medical information regarding breast cancer prevention and did not make exaggerated claims regarding the efficacy of mastectomies. Research has shown that although prophylactic mastectomy substantially reduces (by $\sim 90 \%$ ) the incidence of subsequent breast cancer in women at high risk on the basis of a family history or due to $B R C A 1 / 2$ mutations, it should not be seen as a panacea for breast cancer. ${ }^{37}$ Moreover, physicians do not always agree that mastectomy is the best prevention method and may instead advise very close monitoring (e.g., periodic mammograms and regular clinical breast examinations) or prescribe medications (such as tamoxifen or raloxifene) that decrease the risks of developing breast cancer. ${ }^{38}$

Future research should explore whether the press coverage of Jolie's preventive mastectomy resulted in increased demand and utilization of BRCA1/2 testing and preventive mastectomies. This seems particularly relevant because recent studies have shown that few women have a well-informed understanding of their risk of breast cancer ${ }^{39}$ and that the overemphasis on the impact of genetics in media representations constitutes one of the reasons for misperceptions that many women of all ages have with regard to breast cancer risk. ${ }^{40}$ Media framing of biomedicine is a complex process that may sway public opinion one way or the other by emphasizing certain issues and dismissing others. Although the coverage of Jolie's story highlighted important considerations regarding clinical benefits and access to $B R C A$ testing and preventive medicine, journalists were rarely critical of the phenomenon of celebrity medicine, particularly of how Jolie's mastectomy can influence health choices women make (e.g., only $10.7 \%$ of the articles raised such concerns). Instead, the media presented an overwhelmingly positive slant toward her choice, with less consideration given to arguments for evidence-based assessment of breast cancer risk and preventive options.

\section{SUPPLEMENTARY MATERIAL}

Supplementary material is linked to the online version of the paper at http://www.nature.com/gim

\section{ACKNOWLEDGMENTS}

This study was conducted under the PACEOMICS Project, funded by Genome Canada/Genome Alberta, the Canadian Institute for Health Research (CIHR), and Alberta Health \& Wellness, with additional funding by the CIHR. We also acknowledge the support of the cbcf Tumor Bank, funded by Alberta Innovates Health Solution, the Canadian Breast Cancer Foundation-Prairies Chapters, and the Alberta Cancer Foundation. The authors thank Robyn Hyde-Lay, Ubaka Ogbogu, Christen Rachul, and Brice Goldfelt for their support during the research. T.C. is the Canada Research Chair in Health Law and Policy.

\section{DISCLOSURE}

The authors declare no conflict of interest.

\section{REFERENCES}

1. Jolie A. My Medical Choice. New York Times. 4 May 2013:A25.

2. National Cancer Institute at the National Institutes of Health (NCI). BRCA1 and BRCA2: cancer risk and genetic testing. http://www.cancer.gov/cancertopics/ factsheet/Risk/BRCA.

3. Gold ER, Carbone J. Myriad genetics: in the eye of the policy storm. Genet Med 2010;12(suppl):S39-S70.

4. Adair A, Hyde-Lay R, Einsiedel E, Caulfield T. Technology assessment and resource allocation for predictive genetic testing: a study of the perspectives of Canadian genetic health care providers. BMC Med Ethics 2009;10:6.

5. Williams-Jones B. History of a gene patent: tracing the development and application of commercial BRCA testing. Health Law J 2002;10:123-146.

6. Angell M. Science on Trial: The Clash of Medical Evidence and the Law in the Breast Implant Case. WW Norton: New York, 1998.

7. Ransohoff DF, Ransohoff RM. Sensationalism in the media: when scientists and journalists may be complicit collaborators. Eff Clin Pract 2001;4:185-188.

8. Holtzman NA. Are genetic tests adequately regulated? Science 1999;286: 409.

9. Bubela TM, Caulfield TA. Do the print media "hype" genetic research? A comparison of newspaper stories and peer-reviewed research papers. CMAJ 2004;170:1399-1407

10. Caulfield T. Biotechnology and the popular press: hype and the selling of science. Trends Biotechnol 2004;22:337-339.

11. Association for Molecular Pathology v Myriad Genetics. 569 US 12-398 (2013).

12. Swami V, Taylor R, Carvalho C. Acceptance of cosmetic surgery and celebrity worship: evidence of associations among female undergraduates. Pers Individ Dif 2009;47: 869-872

13. Cram P, Fendrick AM, Inadomi J, Cowen ME, Carpenter D, Vijan S. The impact of a celebrity promotional campaign on the use of colon cancer screening: the Katie Couric effect. Arch Intern Med 2003;163:1601-1605.

14. Mackenzie R, Chapman S, Johnson N, McGeechan K, Holding S. The newsworthiness of cancer in Australian television news. Med J Aust 2008;189:155-158.

15. Chapman S, McLeod K, Wakefield M, Holding S. Impact of news of celebrity illness on breast cancer screening: Kylie Minogue's breast cancer diagnosis. Med J Aust 2005; 183:247-250.

16. Nattinger AB, Hoffmann RG, Howell-Pelz A, Goodwin JS. Effect of Nancy Reagan's mastectomy on choice of surgery for breast cancer by US women. JAMA 1998;279:762-766.

17. Brown ML, Potosky AL. The presidential effect: the public health response to media coverage about Ronald Reagan's colon cancer episode. Public Opin Q 1990;54:317-329.

18. Garrett JM, Bird SJ. Ethical issues in communicating science. Sci Eng Ethics 2000;6:435-442.

19. Friedman SM, Dunwoody S, Rogers CL (eds). Communicating Uncertainty: Media Coverage of New and Controversial Science. Lawrence Erlbaum Associates: Mahwah, NJ, 1999.

20. Miller D, Kitzinger J, Williams K. The Circuit of Mass Communication: Media Strategies, Representation and Audience Reception in the AIDS Crisis. Sage Publications: London, 1998.

21. Entman R. Framing: toward a clarification of a fractured paradigm. J Commun 1993;43:51-58.

22. Scheufele D. Framing as a theory of media effects. J Commun 1999;49: 103-122.

23. Mazur A. Media coverage and public opinion on scientific controversies. J Commun 1981;31:106-115.

24. Nisbet M, Brossard D, Kroepsch A. Framing science: the stem cell controversy in an age of press/politics. IJPP 2003;8:36-70.

25. Caulfield T, Bubela T, Murdoch CJ. Myriad and the mass media: the covering of a gene patent controversy. Genet Med 2007;9:850-855.

26. McCombs ME, Shaw DL. The agenda-setting function of mass media. Public Opin Q 1972;36:176-187.

27. Abelson J. Understanding the role of contextual influences on local healthcare decision making: case study results from Ontario, Canada. Soc Sci Med 2001;53:777-793.

28. Alliance for Audited Media, 2013. http://www.auditedmedia.com/news/ research-and-data/top-25-us-newspapers-for-march-2013.aspx Accessed 30 July 2013. 
29. The Audit Bureau of Circulations, 2013. http://www.abc.org.uk/CertificatesReports/Our-Reports/Accessed 30 July 2013.

30. Dahlgren P, Sparks C. Journalism and Popular Culture. Sage Publications: London, 1992.

31. Lehman-Wilzig S, Seletzky M. Elite and popular newspaper publication of press releases: differential success factors? Public Relat J 2012;6:1-25.

32. Matthes J, Kohring M. The content analysis of media frames: towards improving reliability and vallidity. J Commun 2000;58:258-279.

33. Landis JR, Koch GG. The measurement of observer agreement for categorical data. Biometrics 1977;33:159-174.

34. Leyngold MM, Stutman RL, Khiabani KT, et al. Contributing variables to post mastectomy tissue expander infection. Breast J 2012;18:351-356.

35. Harcourt DM, Rumsey NJ, Ambler NR, et al. The psychological effect of mastectomy with or without breast reconstruction: a prospective, multicenter study. Plast Reconstr Surg 2003;111:1060-1068.
36. Metcalfe KA, Semple J, Quan ML, et al. Changes in psychosocial functioning 1 year after mastectomy alone, delayed breast reconstruction, or immediate breast reconstruction. Ann Surg Oncol 2012:19:233-241.

37. Hartmann LC, Sellers TA, Schaid DJ, et al. Efficacy of bilateral prophylactic mastectomy in BRCA1 and BRCA2 gene mutation carriers. J Natl Cancer Inst 2001;93:1633-1637.

38. Sherry RM. Cancer prevention: role of surgery in cancer prevention. In: DeVita VT Jr, Hellman S, Rosenberg SA (eds). Cancer: Principles and Practice of Oncology, 6th edn. Lippincott Williams and Wilkins: Philadelphia, PA, 2001.

39. Doheny K. Most women don't understand their breast cancer risk: survey. http://healthyliving.msn.com/diseases/breast-cancer/most-women-dontunderstand-their-breast-cancer-risk-survey. Accessed 4 September 2013.

40. Ogata Jones K, Denham BE, Springston JK. Effects of mass and interpersonal communication on breast cancer screening: advancing agenda-setting theory in health contexts. J App/ Commun Res 2006;34:94-113. 